\title{
A new approach to grading and treating COPD based on clinical phenotypes: summary of the Spanish COPD guidelines (GesEPOC)
}

\author{
*Marc Miravitlles ${ }^{1,2}$, Juan José Soler-Cataluña ${ }^{3}$, Myriam Calle ${ }^{4}$, Jesús Molina ${ }^{5}$, \\ Pere Almagro ${ }^{6}$, José Antonio Quintano ${ }^{7}$, Juan Antonio Trigueros ${ }^{8}$, Pascual Piñera ${ }^{9}$, \\ Adolfo Simón ${ }^{10}$, Juan Antonio Riesco ${ }^{2,11}$, Julio Ancochea ${ }^{12}$, Joan B Soriano ${ }^{2,13}$ \\ 1 Servei de Pneumologia, Hospital General Universitari Vall d'Hebron, Barcelona, Spain \\ 2 CIBER de Enfermedades Respiratorias (CIBERES) \\ 3 Unidad de Neumología, Servicio de Medicina Interna, Hospital de Requena, Valencia, Spain \\ 4 Servicio de Neumología, Hospital Clínico San Carlos, Madrid, Spain \\ 5 Centro de Salud Francia, Dirección Asistencial Oeste, Madrid, Spain \\ 6 Servicio de Medicina Interna, Hospital Universitario Mutua de Terrassa, Barcelona, Spain \\ Centro de Salud Lucena I. Lucena, Córdoba, Spain \\ 8 Centro de Salud Menasalbas, Toledo, Spain \\ 9 Servicio de Urgencias, Hospital General Universitario Reina Sofía, Murcia, Spain \\ ${ }^{10}$ Servicio de Urgencias, Hospital General Yagüe, Burgos, Spain \\ ${ }^{11}$ Servicio de Neumología, Hospital San Pedro de Alcántara, Cáceres, Spain \\ ${ }^{12}$ Servicio de Neumología, Hospital Universitario de La Princesa, Instituto de Investigación Sanitaria Princesa (IP), Madrid, Spain \\ ${ }^{13}$ Fundación Caubet-CIMERA Illes Balears, Bunyola, Mallorca, Spain
}

Received 1st November 2012; revised 7th December 2012; accepted 20th December 2012; online 25th February 2013

\begin{abstract}
After the development of the COPD Strategy of the National Health Service in Spain, all scientific societies, patient organisations, and central and regional governments formed a partnership to enhance care and research in COPD. At the same time, the Spanish Society of Pneumology and Thoracic Surgery (SEPAR) took the initiative to convene the various scientific societies involved in the National COPD Strategy and invited them to participate in the development of the new Spanish guidelines for COPD (Guía Española de la EPOC; GesEPOC). Probably the more innovative approach of GesEPOC is to base treatment of stable COPD on clinical phenotypes, a term which has become increasingly used in recent years to refer to the different clinical forms of COPD with different prognostic implications. The proposed phenotypes are: (A) infrequent exacerbators with either chronic bronchitis or emphysema; (B) overlap COPD-asthma; (C) frequent exacerbators with emphysema predominant; and (D) frequent exacerbators with chronic bronchitis predominant. The assessment of severity has also been updated with the incorporation of multidimensional indices. The severity of the obstruction, as measured by forced expiratory volume in 1 second, is essential but not sufficient. Multidimensional indices such as the BODE index have shown excellent prognostic value. If the 6-minute walking test is not performed routinely, its substitution by the frequency of exacerbations (BODEx index) provides similar prognostic properties. This proposal aims to achieve a more personalised management of COPD according to the clinical characteristics and multidimensional assessment of severity.

(C) 2013 Primary Care Respiratory Society UK. All rights reserved.

M Miravitlles et al. Prim Care Respir J 2013; 22(1): 117-121

http://dx.doi.org/10.4104/pcrj.2013.00016
\end{abstract}

Keywords COPD, guidelines, treatment

The full version of this paper, with online appendix,

is available at www.thepcrj.org

\section{Introduction}

The continuous generation of new evidence in any medical area requires that the recommendations be updated for improved

\footnotetext{
* Corresponding author: Dr Marc Miravitlles, Servei de Pneumologia, Hospital General Universitari Vall d'Hebron, Pg. Vall d'Hebron 119-129, 08035 Barcelona, Spain. Tel: 93-274-6157 Fax: 93-274-6083 E-mail: marcm@separ.es
} 
diagnosis and management of patients. In the field of chronic obstructive pulmonary disease (COPD) in particular, there is already a long history of clinical practice guidelines that have allowed physicians from any field to integrate knowledge and to apply the best evidence to their clinical practice. Many of these guidelines have regular updates, ${ }^{1-3}$ and a few also have evaluation mechanisms for their implementation. ${ }^{1}$ However, the volume of knowledge and complexity continues to increase, and a multidisciplinary approach to COPD that includes all stakeholders - including patients themselves - is necessary to try to reduce the huge burden of disease that leads to individual and collective morbidity and mortality.

On 6 October 2009 an integrated COPD Strategy of the National Health Service was adopted in Spain. ${ }^{4}$ All scientific societies, patient organisations, and central and regional governments formed a partnership to enhance care and research in COPD. Related to this, since 2 January 2011 there is a new smoking law in Spain which is more consistent with European Union legislation, ${ }^{5}$ and new plans of action against COPD in various regions started after this date. At the same time, the Spanish Society of Pneumology and Thoracic Surgery (SEPAR) took the initiative to convene the various scientific societies involved in the National COPD Strategy and invited them to participate in the development of the new Spanish guidelines for COPD (Guía Española de la EPOC (GesEPOC); www.gesepoc.com). ${ }^{6}$

GesEPOC ${ }^{7}$ is an ambitious project which is already generating a lively debate about new approaches to the treatment of COPD. We believe that our initiative might be of interest to other colleagues at the international level. This paper summarises the main new approaches of GesEPOC.

\section{Organisation}

GesEPOC has three basic areas of action:

(1) Scientific-Medical, responsible for drafting recommendations aimed at diagnosis and treatment adapted to all levels of healthcare. The final document is structured based on scientific evidence and explicit recommendations that should facilitate their implementation according to the highest standards of care. The document also includes several indicators of quality of care for evaluation of the implementation. ${ }^{6}$

(2) Patients, who are central in any training and self-care strategies, were also involved and developed information materials for patients through focal groups.

(3) Communication, responsible for developing promotional materials, press releases and engaging social and economic factors to generate information about COPD and those who suffer. $^{\text {? }}$

As discussed above, representatives from all the scientific societies represented within GesEPOC (see Appendix 1, available online at www.thepcrj.org) discussed COPD treatment recommendations, which were updated on the basis of the advances that have emerged in recent years. Perhaps our more innovative approach is to base the treatment of stable COPD on clinical phenotypes, a term which has become increasingly used in recent years to refer to the different clinical forms of patients with
COPD. Recently, a group of international experts defined clinical phenotypes of COPD as "... those attributes of the disease alone or in combination that describe the differences between individuals with COPD in relation to parameters that have clinical significance (symptoms, exacerbations, response to treatment, rate of progression disease, or death)" ${ }^{8}$ The phenotype should therefore be able to classify patients into subgroups with prognostic value and determine the most appropriate therapy to achieve better results from a clinical standpoint.

\section{Phenotypes of COPD}

Many previous studies have attempted to identify and quantify the prevalence of different phenotypes of COPD using populations of various sources, severities, and particularities. ${ }^{9}$ Yet there is no consensus on the number and definition of different phenotypes, from two to 210 million (the estimated number of patients worldwide). However, there must be a compromise between the oversimplification of the term COPD as a definition that encompasses the entire spectrum of patients with incompletely reversible airflow obstruction caused largely by smoking and the complexity of considering each patient individually as an orphan disease. ${ }^{10}$ This intermediate step might arise by the identification and description of some phenotypes, not only in the biological or epidemiological sense but also from the prognostic and therapeutic point of view, especially at the individual patient level. After a lengthy but fruitful panel discussion, it was proposed that four different phenotypes of prognostic and therapeutic relevance characterised by the combination of the classical types of emphysema, chronic bronchitis, exacerbators and patients with overlap COPD-asthma be defined." The proposed phenotypes are: (A) infrequent exacerbators with either chronic bronchitis or emphysema; (B) overlap COPD-asthma; (C) frequent exacerbators with emphysema predominant; and (D) frequent exacerbators with chronic bronchitis predominant (Figure 1). We describe the rationale behind each of these four phenotypes, and their proposed treatment. ${ }^{12}$

\section{Infrequent exacerbators with either chronic bronchitis or emphysema}

Infrequent exacerbators are defined as patients experiencing $<2$ exacerbations per year. ${ }^{13}$ The importance of identifying this phenotype is that there is currently no anti-inflammatory treatment indicated for infrequent exacerbators. The treatment of this phenotype is based on bronchodilators, alone or in combination, and together with theophyllines in severe cases.

\section{Overlap COPD-asthma}

The overlap COPD-asthma phenotype is characterised by incompletely reversible obstruction of airflow accompanied by symptoms or signals of increased reversibility of the obstruction. . $^{14-16}$ Epidemiological studies of COPD incidence show that young patients with asthma who smoke and develop airflow obstruction that is not fully reversible (i.e. COPD) have a disease with different characteristics from those with no history of asthma. In the first case, allergic rhinitis, bronchial hyperresponsiveness, and the presence of wheezing as well as higher plasma concentrations of IgE are 
Figure 1. Chronic obstructive pulmonary disease (COPD) clinical phenotypes. Reproduced with permission from Miravitlles et al. ${ }^{12}$

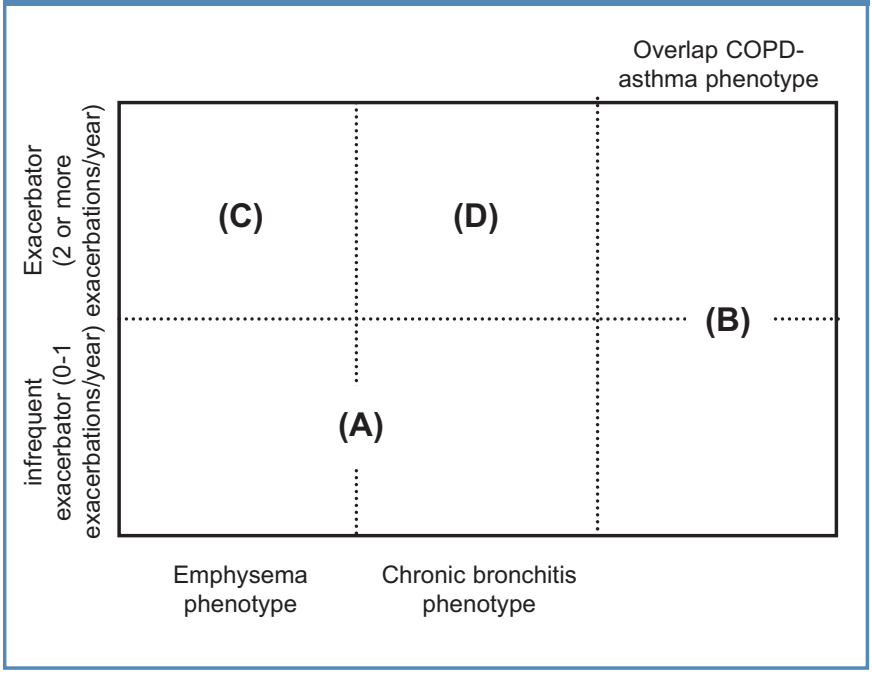

significantly more frequent, indicating that this is an overlap phenotype between asthma and COPD. ${ }^{17}$ Also, asthma by itself is a risk factor for the development of chronic airflow obstruction, particularly if undertreated, and in advanced stages may be indistinguishable from smokers' COPD. ${ }^{18}$ The prevalence of this mixed phenotype is unknown, but there are different estimates of its importance in the context of COPD. COPDGene estimated it was $13 \%$ of their sample. ${ }^{19}$ Soriano et al. estimated that approximately $23 \%$ of COPD patients aged $50-59$ years could have a mixed phenotype, increasing to $52 \%$ of those with COPD aged $70-79$ years. ${ }^{9}$ The relevance of this phenotype, already described in the Canadian and Japanese guidelines, ${ }^{2,3}$ is its enhanced response to inhaled corticosteroids, which must be prescribed together with long-acting bronchodilators irrespective of the severity of the airflow obstruction. Recently, a group of experts have proposed a series of criteria for the diagnosis of the overlap phenotype of asthma and COPD..$^{20}$

\section{Frequent exacerbators with emphysema or chronic bronchitis predominant}

The COPD exacerbator phenotype refers to patients experiencing $\geq 2$ exacerbations annually. ${ }^{13}$ This phenotype is based on clinical records and/or patient recall, and it has been shown that diagnosis based on the patient's statement about his/her history of exacerbations is reliable. ${ }^{21}$ The COPD exacerbator phenotype underscores the importance of asking about the history of exacerbations in the clinical interview and identifies patients who may require antiinflammatory treatment added to bronchodilators.

When the exacerbator patient does not present with chronic cough and sputum production and the typical clinical and radiological signs of emphysema can be identified (air trapping, dyspnoea, and a tendency to low body mass index), it constitutes the exacerbator with emphysema phenotype. The basis of pharmacological treatment is long-acting bronchodilators and, in some cases, with inhaled corticosteroids. The diagnosis of predominant emphysema can be established in patients without daily cough and sputum production and with clinical and radiographical signs of air trapping. In controversial cases, the determination of static lung volumes and/or a chest CT scan will be of help.

More frequently, the exacerbator will present with chronic bronchitis, ${ }^{22}$ defined as the presence of productive cough or expectoration for $>3$ months a year and for more than two consecutive years. Bronchial hypersecretion in COPD has been associated with increased airway inflammation and increased risk of bronchial colonisation and respiratory infection, which may explain why patients with chronic bronchitis have an increased frequency of exacerbations. ${ }^{23}$ These patients may be treated with bronchodilators, inhaled corticosteroids and, in contrast to exacerbators with emphysema, they respond to treatment with roflumilast. Selected cases with frequent exacerbations may respond to long-term treatment with macrolides ${ }^{24}$ and, when inhaled corticosteroids cannot be used, mucolytics may be effective in reducing exacerbations..$^{25}$

\section{Assessment of severity}

These phenotypes identify patients with different responses to the available treatments and allow a more personalised approach to treatment, which will be modulated by the severity. The assessment of severity has also been updated with the incorporation of multidimensional indices. The severity of obstruction, as measured by forced expiratory volume in 1 second $\left(\mathrm{FEV}_{1}\right)$ is essential but not sufficient. Multidimensional indices such as the BODE index (body mass index, airflow obstruction, dyspnoea, and exercise capacity) have demonstrated excellent prognostic value. ${ }^{26,27}$ If the 6-minute walking test is not performed routinely, its substitution by the frequency of exacerbations (BODEx index) provides similar prognostic properties. ${ }^{28}$ For those physicians not familiar with indices, GesEPOC proposes to establish the severity of COPD based on the combination of $\mathrm{FEV}_{1}$, dyspnoea measured by the modified MRC scale, level of physical activity quantified as the mean time in minutes that the patient walks per day, ${ }_{1}{ }^{29}$ and history of previous hospitalisations. ${ }^{12}$ For all degrees of severity, the COPD Assessment Test (CAT) score and the number of exacerbations will serve as a marker of disease control..$^{30} \mathrm{~A}$ summary of the evaluation of severity is presented in Figure 2. In GesEPOC we recommend directing the type of treatment by phenotype and the intensity of treatment by its severity, as shown in Table 1.

\section{A step to the future}

We recognise that this approach represents a significant change in the management of COPD, from an approach focused on the severity of airflow limitation to a more personalised approach focused on clinical features and a multidimensional evaluation of severity. ${ }^{31}$ Parallel to this clinical approach, GesEPOC wants to highlight the crucial role of patients and their caregivers in improving outcomes of care. To achieve the best possible results, it includes specific strategies such as a guide to COPD for patients, personalised action plans, and the performance of 'expert patients' 
Figure 2. Evaluation of severity in the GesEPOC guidelines.

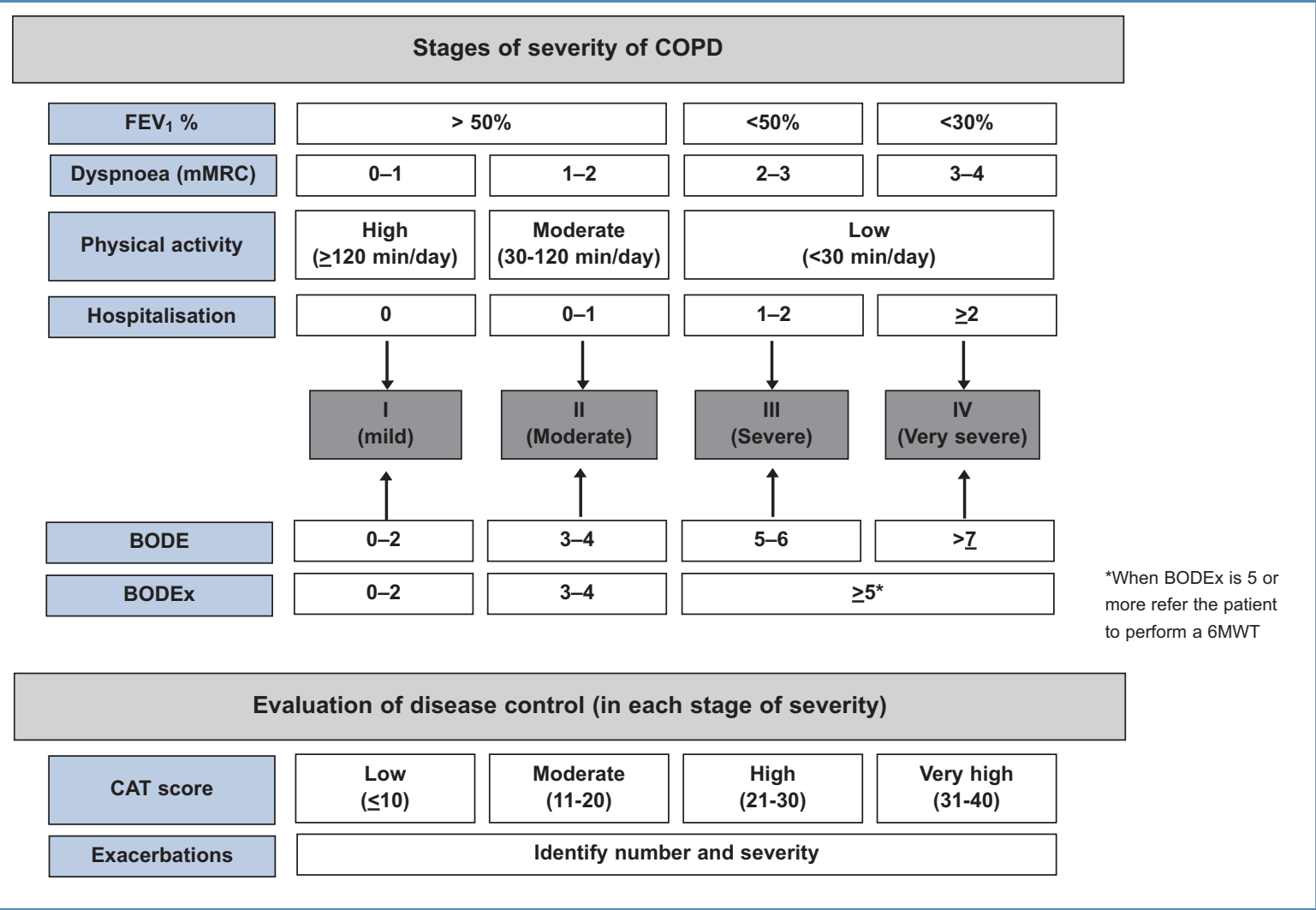

Table 1. Proposal of pharmacological treatment of COPD based on clinical phenotypes and severity

\begin{tabular}{|c|c|c|c|c|}
\hline \multirow[b]{2}{*}{ Phenotype } & \multicolumn{4}{|l|}{ Severity stages } \\
\hline & 1 & II & III & IV \\
\hline $\begin{array}{l}\text { A } \\
\text { Infrequent exacerbator }\end{array}$ & $\begin{array}{l}\text { LAMA or LABA } \\
\text { SABA or SAMA* }\end{array}$ & $\begin{array}{l}\text { LAMA or LABA } \\
\text { LAMA+ LABA }\end{array}$ & LAMA+ LABA & LAMA + LABA + theophylline \\
\hline $\begin{array}{l}\text { B } \\
\text { Overlap COPD-asthma }\end{array}$ & $L A B A+I C S$ & LABA + ICS & $L A M A+L A B A+I C S$ & $\begin{array}{l}\text { LAMA + LABA +ICS } \\
\text { (consider adding theophylline or } \\
\text { PDE4I if there is expectoration) }\end{array}$ \\
\hline $\begin{array}{l}\mathrm{C} \\
\text { Exacerbator with emphysema }\end{array}$ & LAMA or LABA & $\begin{array}{l}(\text { LABA or LAMA })+I C S \\
\text { LAMA + LABA } \\
\text { LAMA or LABA }\end{array}$ & $L A M A+L A B A+C I$ & $\begin{array}{l}\text { LAMA + LABA + ICS } \\
\text { (consider adding theophylline) }\end{array}$ \\
\hline $\begin{array}{l}\mathrm{D} \\
\text { Exacerbator with chronic } \\
\text { bronchitis }\end{array}$ & LAMA or LABA & $\begin{array}{l}\text { (LAMA or LABA) + } \\
\text { (ICS or PDE4I) } \\
\text { LAMA + LABA } \\
\text { LAMA or LABA }\end{array}$ & $\begin{array}{l}\text { LAMA + LABA + (ICS or } \\
\text { PDE4I) } \\
\text { (LAMA or LABA) + ICS + } \\
\text { PDE4I } \\
\text { (consider adding carbocisteine) }\end{array}$ & $\begin{array}{l}\text { LAMA + LABA + (ICS or PDE4I) } \\
\text { LAMA + LABA + ICS + PDE4I } \\
\text { (consider adding carbocisteine) } \\
\text { (consider adding theophylline) } \\
\text { (consider adding antibiotics) }\end{array}$ \\
\hline
\end{tabular}

or group visits directed to improve the skills and abilities in health of patients and caregivers. All of these strategies have been developed with the active participation of the Spanish associations of COPD patients.

A change of this magnitude requires input and, finally, the consensus views of a significant number of professionals working with COPD and patients themselves. Since the beginning of the guideline process it has been presented at meetings and has received and integrated comments from more than 150 health professionals and independent reviewers.

GesEPOC was born with a desire for continuity, to explore new platforms for communication with physicians, patients, media and health authorities and the implementation and evaluation of their impact on the treatment of COPD, without forgetting its role in 
spreading the awareness of this disease among the general population and at the political level. Together with the official website, the main aspects of the guideline will be available in the form of Apps for iPad, iPod, and Android.

We hope that this initiative will contribute to the debate about new approaches to the management of COPD and will provide a more personalised treatment for patients with this frequent chronic disease.

\section{Handling editor Jaime Correia de Sousa}

Conflicts of interest $\mathrm{MM}$ has received honoraria for lecturing or scientific advice from Boehringer Ingelheim (BI), Pfizer, AstraZeneca (AZ), Bayer Healthcare, Novartis, Talecris, Takeda-Nycomed, Merck, Sharp \& Dohme (MSD), Novartis, GlaxoSmithKline (GSK) and Almirall. PA has received honoraria for lecturing, research funds or scientific advice from Bl, Pfizer, Takeda-Nycomed, MSD, Almirall, GSK, Chiesi and Esteve. JA has received honoraria for lecturing, research funds or scientific advice from BI, Novartis, Takeda-Nycomed, Almirall, GSK, Intermunne, Faes Farma, Chiesi and Actelion. MC has received honoraria for lecturing, research funds or scientific advice from Carburos Médica, AZ, MSD and Almirall. JJS-C has received honoraria for lecturing, research funds or scientific advice from BI, Pfizer, AZ, Bayer Schering, Novartis, Takeda-Nycomed, MSD, Almirall, Grupo Ferrer, GSK and Vifor Pharma. JBS has received honoraria for lecturing, research funds or scientific advice from Almirall. JAT has received honoraria for lecturing, research funds or scientific advice from BI, Pfizer and Bayer Healthcare. JM, PP, JAQ, JAR and AS have no conflict of interest in relation to this article.

Contributorship MM and JJS-C drafted the manuscript. All authors participated in the different steps of development of the guidelines and critically reviewed the manuscript.

Funding GesEPOC has been funded by an unrestricted grant from Almirall, AstraZeneca, Bayer Healthcare, Boehringer Ingelheim-Pfizer, Faes Farma, Grupo Ferrer, GlaxoSmithKline, Novartis, Takeda-Nycomed, Chiesi, Esteve-Teijin, and Vitor Pharma Spain.

\section{References}

1. National Clinical Guideline Centre. Chronic obstructive pulmonary disease: management of chronic obstructive pulmonary disease in adults in primary and secondary care. 2010. London: National Clinical Guideline Centre. Available from: http://guidance.nice.org.uk/CG101/Guidance/pdf/English

2. O'Donnell DE, Aaron S, Bourbeau J, et al. Canadian Thoracic Society recommendations for management of chronic obstructive pulmonary disease 2007 update. Can Respir J 2007;14(Suppl B):5-32B.

3. Nagai A, Aizawa H, Aoshiba K, et al. Guidelines for the diagnosis and treatment of COPD. 3rd ed. Tokyo: The Japanese Respiratory Society Medical Review Co Ltd, 2009.

4. Estrategia del Sistema Nacional de Salud en EPOC. Ministerio de Salud y Política Social, Madrid, 2009

5. Boletin Oficial del Estado. Ley $42 / 2010$, de 30 de diciembre, por la que se modifica la Ley 28/2005, de 26 de diciembre, de medidas sanitarias frente al tabaquismo y reguladora de la venta, el suministro, el consumo y la publicidad de los productos del tabaco.

6. Soler-Cataluña JJ, Calle M, Cosio BG, Marín JM, Monso E, Alfageme I. Helathcare quality standards in chronic obstructive pulmonary disease. Arch Bronconeumol 2009;45:361-2. http://dx.doi.org/10.1016/ j.arbres.2009.05.001

7. Grupo de Trabajo de GesEPOC. Guía de Práctica Clínica para el diagnóstico y tratamiento de pacientes con enfermedad pulmonar obstructiva crónica (EPOC) - Guía Española de la EPOC (GesEPOC). Arch Bronconeumol 2012;48(Supl 1):258.

8. Han MK, Agusti A, Calverley PM, et al. Chronic obstructive pulmonary disease phenotypes: the future of COPD. Am J Respir Crit Care Med 2010;182:598-604 http://dx.doi.org/10.1164/rccm.200912-1843CC

9. Soriano JB, Davis KJ, Coleman B, Visick G, Mannino D, Pride NB. The proportional Venn diagram of obstructive lung disease: two approximations from the United States and the United Kingdom. Chest 2003;124:474-81. http://dx.doi.org/10.1378/chest.124.2.474
10. Rennard SI, Vestbo J. The many "small COPDs": COPD should be an orphan disease. Chest 2008;134(3):623-7. http://dx.doi.org/10.1378/chest.07-3059

11. Miravitlles M, Calle $M$, Soler-Cataluña JJ. Clinical phenotypes of COPD. Identification, definition and implications for guidelines. Arch Bronconeumol 2012;48:86-98. http://dx.doi.org/10.1016/j.arbr.2012.01.003

12. Miravitlles M, Soler-Cataluña JJ, Calle $M$, et al. Spanish COPD guidelines (GesEPOC). Pharmacological treatment of stable COPD. Arch Bronconeumol 2012;48:247-57. http://dx.doi.org/10.1016/j.arbr.2012.05.003

13. Hurst JR, Vestbo J, Anzueto A, et al. Susceptibility to exacerbation in chronic obstructive pulmonary disease. N Engl J Med 2010;363:1128-38. http://dx.doi.org/10.1056/NEJMoa0909883

14. Gibson PG, Simpson JL. The overlap syndrome of asthma and COPD: what are its features and how important is it? Thorax 2009;64:728-35. http://dx.doi.org/10.1136/thx.2008.108027

15. Piras B, Miravitlles M. The overlap phenotype: the (missing) link between asthma and COPD. Multidiscip Respir Med 2012;7:8. http://dx.doi.org/ 10.1186/2049-6958-7-8

16. Miravitlles M. The overlap síndrome between asthma and COPD: implications for management. Hot Topics Respir Med 2011;16:15-20.

17. De Marco R, Accordini S, Cerveri I, et al. Incidence of chronic obstructive pulmonary disease in a cohort of young adults according to the presence of chronic cough and phlegm. Am J Respir Crit Care Med 2007;175:32-9. http://dx.doi.org/10.1164/rccm.200603-3810C

18. Silva GE, Sherrill DL, Guerra S, Barbee RA. Asthma as a risk factor for COPD in a longitudinal study. Chest 2004;126:59-65. http://dx.doi.org/10.1378/ chest.126.1.59

19. Hardin M, Silverman EK, Barr RG, et al. The clinical features of the overlap between COPD and asthma. Respir Res 2011;12:127. http://dx.doi.org/ 10.1186/1465-9921-12-127

20. Soler-Cataluña JJ, Cosío B, Izquierdo JL, et al. Consensus document on the overlap phenotype COPD-asthma in COPD. Arch Bronconeumol 2012;48:331-7. http://dx.doi.org/10.1016/j.arbr.2012.06.017

21. Quint JK, Donaldson GC, Hurst JR, Goldring JJP, Seemungal TR, Wedzicha JA Predictive accuracy of patient-reported exacerbation frequency in COPD. Eur Respir J 2011;37:501-7. http://dx.doi.org/10.1183/09031936.00035909

22. Kim V, Han MK, Vance GB, et al. The chronic bronchitic phenotype of COPD. An analysis of the COPDGene study. Chest 2011;140:626-33. http://dx.doi.org/10.1378/chest.10-2948

23. Miravitlles M. Cough and sputum production as risk factors for poor outcomes in patients with COPD. Respir Med 2011;105:1118-28. http://dx.doi.org/ 10.1016/j.rmed.2011.02.003

24. Albert RK, Connett J, Biley WC, et al. Azithromycin for prevention of exacerbations of COPD. N Engl J Med 2011;365:689-98. http://dx.doi.org/ 10.1056/NEJMoa1104623

25. Poole PJ, Black PN. Mucolytic agents for chronic bronchitis or chronic obstructive pulmonary disease. Cochrane Database Syst Rev 2006: (3):CD001287

26. Celli BR, Cote CG, Marín JM, et al. The body-mass index, airflow obstruction, dyspnea, and exercise capacity index in chronic obstructive pulmonary disease. N Engl J Med 2004;350:1005-12. http://dx.doi.org/10.1056/NEJMoa021322

27. Marin JM, Alfageme I, Almagro $P$, et al. Multicomponent indices to predict survival in COPD: the COllaborative COhorts to assess Multicomponent Indices of COPD in Spain-COCOMICS study. Eur Respir J 2012 Dec 6 [Epub ahead of print]. http://dx.doi.org/10.1183/09031936.00121012

28. Soler-Cataluña JJ, Martínez-García MA, Sánchez LS, Tordera MP, Sánchez PR. Severe exacerbations and BODE index: two independent risk factors for death in male COPD patients. Respir Med 2009;103:692-9. http://dx.doi.org/10.1016/j.rmed.2008.12.005

29. Esteban C, Quintana JM, Aburto M, et al. Impact of changes in physical activity on health-related quality of life among patients with COPD. Eur Respir $J$ 2010;36:292-300. http://dx.doi.org/10.1183/09031936.00021409

30. Jones PW, Brusselle G, Dal Negro RW, et al. Properties of the COPD assessment test in a cross-sectional European study. Eur Respir J 2011;38:29-35. http://dx.doi.org/10.1183/09031936.00177210

31. Miravitlles M, Soler-Cataluña JJ, Calle M, Soriano J. Treatment of COPD by clinical phenotypes. Putting old evidence into clinical practice. Eur Respir J 2012 Oct 11 [Epub ahead of print]. http://dx.doi.org/10.1183/09031936.00118912 


\section{Appendix 1. Structure of the GesEPOC Group}

Coordinator: Marc Miravitlles, Spanish Society of Pneumology and Thoracic Surgery (SEPAR).

Members of the Working Group: Myriam Calle, Juan José Soler-Cataluña, SEPAR; Joan B Soriano, SEPAR-Epidemiology; Julio Ancochea, Scientific Coordinator, COPD Strategy of the National Health Service. Joan Escarrabill, Director del Pla Director de les Malalties de I'Aparell Respiratori (PDMAR) del Departament de Salut, Barcelona. Pere Almagro, Spanish Society of Internal Medicine (SEMI). Daniel López, SEPARPhysiotherapy. Ester Marco, Spanish Society of Rehabilitation and Physical Medicine and Spanish Society of Cardio-Respiratory Rehabilitation (SERMEF/SORECAR). Juan Antonio Riesco, National Committee of Smoking Prevention (CNPT). José Antonio Quintano, Spanish Society of Primary Care Medicine (SEMERGEN). Juan Antonio Trigueros, Spanish Society of General and Family Medicine (SEMG). Jesús Molina, Spanish Society of Family and Community Medicine (semFYC) and Society of Respiratory in Primary Care (GRAP). Mercè Marzo, semFYCMethodology. Pascual Piñera, Adolfo Simón, Spanish Society of Urgencies and Emergency Medicine (SEMES). Antonia Cachinero, SEPARNursery. María Dolors Navarro, Spanish Forum of Patients (FEP). Montse Llamas, UOC-AlaOeste-Communication. 